\title{
Influência das águas do estuário do Rio Pará na fertilidade do solo das ilhas de várzea em Belém, Pará
}

\author{
Sérgio Brazão e Silva \\ Jessivaldo Rodrigues Galvão * \\ Joberta Cardoso Pastana \\ Deivison Rodrigues da Silva \\ Karine Costa de Almeida \\ Francisco José Lima de Souza \\ Ilano Silva Braga do Nascimento
Universidade Federal Rural da Amazônia, Campus Belém, Instituto de Ciências Agrárias Avenida Tancredo Neves, 2501, Caixa Postal 917, CEP 66077-580, Belém - PA, Brasil
* Autor para correspondência
jessigalvao50@gmail.com

Submetido em 08/03/2018

Aceito para publicação em 22/10/2018

\section{Resumo}

O Rio Pará é um imenso estuário formado por diversos rios e baías, compondo um grande contingente de água doce para o oceano. Nesse ambiente, encontram-se muitas ilhas, sendo 39 pertencentes à cidade de Belém. São ilhas com pouca porcentagem de área de terra firme, com presença de áreas cultivadas por agricultores familiares. O trabalho teve como objetivo avaliar o efeito da movimentação da água do estuário do Rio Pará na fertilidade do solo das ilhas de Belém, Pará. A amostragem foi realizada em 23 ilhas em ecossistema de várzea com área superior a 10 ha, incluindo as três maiores que possuem significativa área de terra firme (Mosqueiro, Caratateua e Cotijuba) e três ilhas pertencentes ao município de Ananindeua, situadas ao sul de Mosqueiro (Mutum, Santa Rosa e João Pilatos). As amostras foram coletadas em ambiente ribeirinho, contornando as ilhas, procurando contemplar as áreas exploradas pela população. O estudo indica que existe variabilidade na fertilidade do solo no ambiente insular de Belém, com diferença significativa entre os arquipélagos avaliados, para os teores de Cálcio $\left(\mathrm{Ca}^{+2}\right)$, Magnésio $\left(\mathrm{Mg}^{+2}\right)$, Potássio $\left(\mathrm{K}^{+}\right)$e Alumínio $\left(\mathrm{Al}^{+3}\right)$, além da Soma de Bases (SB) e Capacidade de Troca Catiônica (CTC). Não se observou diferença significativa para os valores de Fósforo disponível (P). Observou-se também um gradiente decrescente na direção sul-norte para o $\mathrm{K}^{+}$e o pH.

Palavras-chave: Hidrografia; Nutrientes; Várzea

\section{Abstract}

Influence of water of the Rio Pará estuary on soil fertility of várzea islands in Belém, Pará. The Pará River is an immense estuary formed by numerous rivers and bays, composing a large body of fresh water that flows into the ocean. In this environment, there are many islands, of which 39 belong to the city of Belém. These 
islands have a small percentage of terra firma, including areas cultivated by family farmers. The objective of this study was to evaluate the effect of the water movement of the Pará River estuary on soil fertility of islands of Belém, Pará. Sampling was carried out on 23 islands in a várzea ecosystem with an area greater than 10 ha, including three significantly large islands (Mosqueiro, Caratateua and Cotijuba) and three islands (Mutum, Santa Rosa and João Pilatos) that belong to the municipality of Ananindeua, located south of Mosqueiro. The samples were collected in a riverine environment, surrounding the islands, with the goal of better understanding the areas used by the local population. The study indicates that there is variability in the soil fertility of insular environments of Belém, including a significant difference between the archipelagos evaluated for calcium $\left(\mathrm{Ca}^{+2}\right)$, magnesium $\left(\mathrm{Mg}^{+2}\right)$, potassium $\left(\mathrm{K}^{+}\right)$and aluminum $\left(\mathrm{A}^{+3}\right)$, as well as the sum of bases $(\mathrm{SB})$ and cation exchange capacity (CTC). No significant difference was observed for the values of available phosphorus (P). A gradient in the south-north direction was also observed for the elements $\mathrm{K}^{+}, \mathrm{Mg}^{+2}$ and $\mathrm{Al}^{+3}$.

Key words: Hydrography; Nutrients; Plant diversity

\section{Introdução}

Na Amazônia, a maior parte dos estudos sobre caracterização química do solo foi realizada para as áreas de terra firme. Atualmente, pouco se conhece sobre o efeito do uso da terra nos solos de várzea por serem esses de formação sedimentar e por estarem sujeitos às ações de remoção, transporte e deposição ocasionados, principalmente, pelo ciclo das águas.

O estuário do Rio Pará é formado por diversos rios e baías, compondo um grande contingente de água doce para o oceano. É um conjunto hidrográfico que não possui nascente própria e reúne o produto dos rios Acará e Guamá. Nesse ambiente, encontram-se muitas ilhas, algumas delas circundando a cidade de Belém, sendo 39 pertencentes a esse município (LIMA et al., 2001).

O ambiente de terra firme só existe significativamente nas ilhas de Mosqueiro, Caratateua e Cotijuba. As 36 ilhas restantes são, predominantemente, áreas de várzea com importância para a manutenção da condição ambiental da cidade, para a moradia da população rural e abastecimento de alimentos para as feiras do município de Belém (SILVA et al., 2010).

A extrema importância das áreas de várzea destaca a sua condição de abrigo para um grande número de espécies vegetais adaptadas à inundação e uma interação dinâmica entre as cadeias alimentares dos rios. Estudos apontam para o fato de que as áreas de várzea possuem alta produção de biomassa, sendo a mata uma rica fonte de alimento para os peixes dos rios e lagos, $90 \%$ destes frugívoros. Estudos estimam que $25 \mathrm{~km}^{2}$ são cobertos por ecossistemas de mata inundável, dos quais $88 \%$ estão submetidos a um regime de inundações frequentes. Assim, o sistema de cheia e vazante, verificado nas áreas de várzea, contribui para a constituição de um ambiente singular de fertilidade (FERREIRA, 2014).

A várzea é o local de habitação da população ribeirinha que, por sua vez, faz uso da área em diversas atividades, sendo a maioria relacionada ao extrativismo. A permanência dessa população no local é associada a relatos que indicam a existência de níveis adequados de fertilidade do solo, sem, entretanto, terem sido avaliados.

Embora alguns autores afirmem que a salinidade no Rio Pará somente se eleve próximo à sua foz, especificamente nos municípios de Vigia, São Caetano de Odivelas, Salvaterra e Soure, Lima et al. (2001) chamam atenção para a influência da água do mar mais adentro do continente.

É apresentada a hipótese de o solo da várzea ser influenciado pela água de inundação, que pode ter seus sítios de troca ocupados por cátions existentes na água em quantidades elevadas (SILVA et al., 2010). A partir disso, o trabalho teve como objetivo avaliar o efeito da água do estuário do Rio Pará na fertilidade do solo das ilhas de Belém-Pará.

\section{Material e Métodos}

A cidade de Belém - PA situa-se a 01²7'20”S e 48³0'15'W. Limita-se, ao norte, com a Baía do Marajó; ao leste, com os municípios de Santo Antônio do Tauá, Ananindeua, Santa Bárbara e Marituba; ao sul, com o 
município de Acará; e, ao oeste, com as Baías do Guajará e do Marajó (Figura 1). No ambiente rural de Belém, está localizado o Rio Pará, onde se distinguem três arquipélagos, denominados conforme a sua localização: Arquipélago Sul, Arquipélago Oeste e Arquipélago Norte (LIMA et al., 2001).
A amostragem foi realizada em 23 ilhas com ecossistema de várzea, incluindo as três maiores que possuem significativa área de terra firme (Mosqueiro, Caratateua e Cotijuba) e três ilhas pertencentes ao município de Ananindeua, situadas ao sul de Mosqueiro

FIGURA 1: Belém e sua região insular.

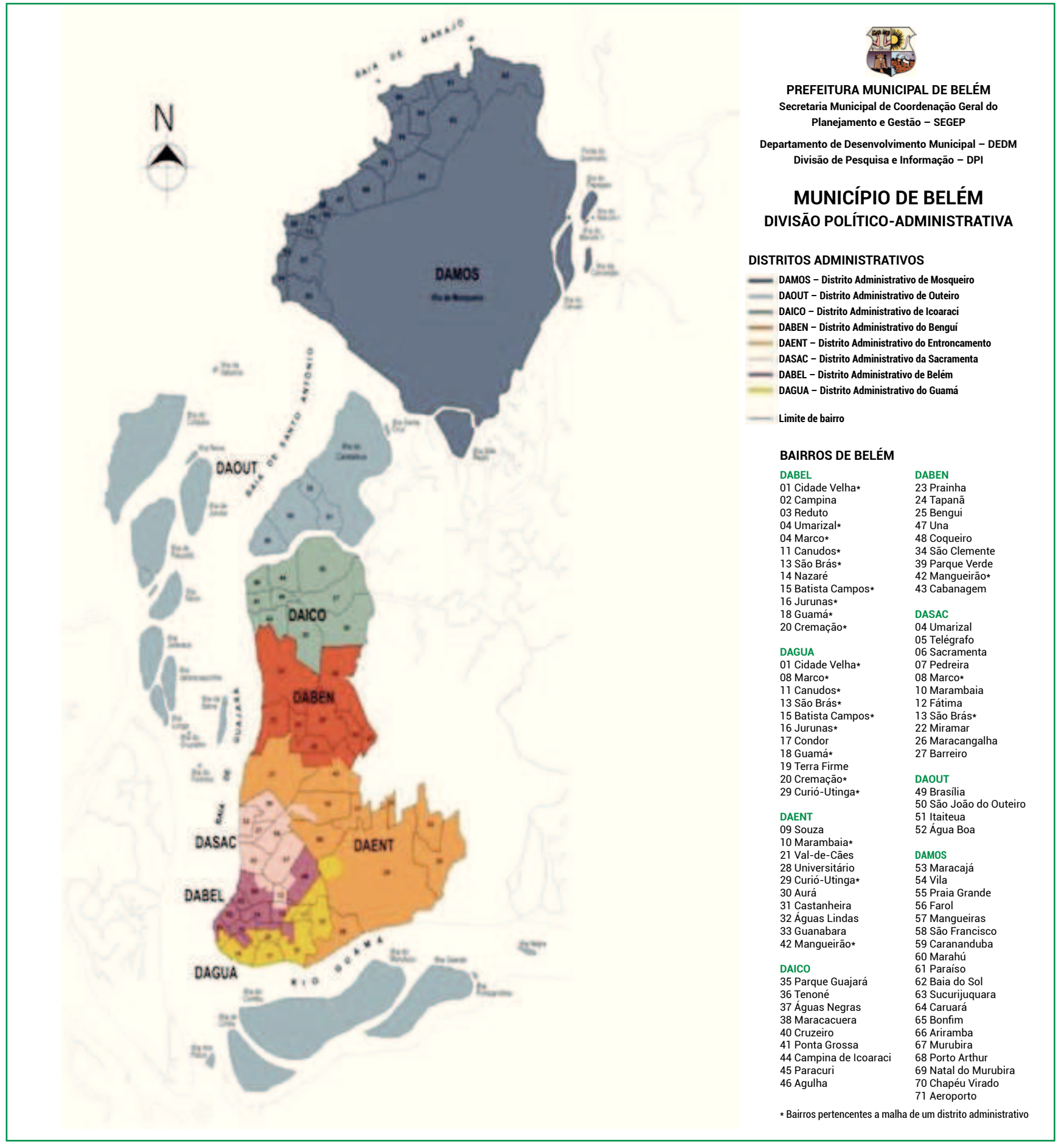


(Mutum, Santa Rosa e João Pilatos). Foram excluídas as ilhas com menos de 10 ha, estando a maioria desabitada, constituídas apenas de várzea em cota baixa.

O clima predominante na região é o Afi, de acordo com classificação de Köppen, com temperatura média anual de $26^{\circ} \mathrm{C}$, alta pluviosidade $(2.754,4 \mathrm{~mm}$ anuais), ocorrendo uma estação chuvosa, de dezembro a maio, e uma menos chuvosa, de junho a novembro. O estudo foi conduzido durante o período de menor intensidade pluviométrica, em virtude do baixo nível da água e da maré, facilitando a coleta do solo e a locomoção nas ilhas.

As amostras foram coletadas em quatro expedições contornando as ilhas e adentrando em furos e igarapés, procurando contemplar as áreas exploradas pela população. As amostras foram obtidas da camada superficial do solo, na profundidade de $0-20 \mathrm{~cm}$, com uma distância de $0,5 \mathrm{~km}$ a $1 \mathrm{~km}$ entre os pontos de coleta, utilizando trado holandês. Foram coletadas 360 amostras, correspondentes a 62 no Arquipélago Sul (quatro ilhas), 100 no Arquipélago Oeste (sete ilhas) e 198 no Arquipélago Norte (12 ilhas).

As coletas foram submetidas à determinação de $\mathrm{pH}$, fósforo disponível, cálcio, magnésio, além de potássio e alumínio trocável e granulometria. As análises aconteceram no Laboratório de Solos da Universidade Federal Rural da Amazônia (UFRA), empregando o descrito por Silva (2003) e EMBRAPA (2009). A classificação da concentração dos nutrientes foi feita de acordo com Cravo et al. (2007).

O delineamento experimental foi inteiramente casualizado, comparando os atributos químicos e físicos obtidos para cada arquipélago. Os resultados foram tratados estatisticamente, considerando a variância e comparados pelo teste de Tukey ao nível de significância de $5 \%$.

\section{Resultados}

$\mathrm{Na}$ Tabela 1, encontra-se o resumo da análise de variância para o pH, Fósforo disponível (P), Cálcio $\left(\mathrm{Ca}^{+2}\right)$, Magnésio $\left(\mathrm{Mg}^{+2}\right)$, Potássio $\left(\mathrm{K}^{+}\right)$e Alumínio $\left(\mathrm{Al}^{+3}\right)$ trocáveis nos arquipélagos, aplicando-se o teste de Tukey ao nível de 5\% de significância.

TABELA 1: Resultados da análise de variância.

\begin{tabular}{cccccccc}
\hline Fonte & $\mathbf{G . ~ L . ~}$ & $\begin{array}{c}\mathbf{p H} \\
\left(\mathbf{H}_{2} \mathbf{O}\right)\end{array}$ & $\mathbf{P}$ & $\mathbf{C a}^{+2}$ & $\mathbf{M g}^{+2}$ & $\mathbf{K}^{+}$ & $\mathbf{A l}^{+3}$ \\
\hline Local & 2 & & $(\mathrm{mg}$. & & $\left(\mathrm{cmol} . \mathrm{dm}^{3}\right)$ & \\
Erro & 147 & & $\left.\mathrm{dm}^{3}\right)$ & & & & \\
Q. M. & - & $1,23^{*}$ & $28^{\mathrm{NS}}$ & $2,19^{\mathrm{NS}}$ & $7,79^{* *}$ & $0,99^{*}$ & $5,89^{* *}$ \\
$\begin{array}{l}\text { Média } \\
\text { Geral }\end{array}$ & - & 4,94 & 11,81 & 2,74 & 4,12 & 0,22 & 1,14 \\
\hline
\end{tabular}

** Significativo ao nível de 5\%; * Significativo ao nível de 1\%; NS: Não significativo.

Os resultados demostraram diferença significativa entre as concentrações dos nutrientes no solo dos três arquipélagos, assim como também para o $\mathrm{pH}$ e $\mathrm{Al}^{3+}$. Observa-se um gradiente de diminuição de valores, na direção norte-sul, para o $\mathrm{pH}$ e $\mathrm{Al}^{3+}$, diferentemente do

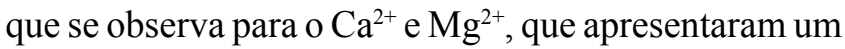
aumento da concentração desses nutrientes no sentido norte-sul. A concentração de $\mathrm{P}$ e de $\mathrm{K}^{+}$foi mais elevada nos solos das ilhas ao norte. A Figura 2 ilustra a variação entre os dados obtidos nos arquipélagos.

$\mathrm{O}$ pH obtido variou de 4,8 a 5,4, valor que classifica os solos dos três arquipélagos como mediamente ácido (Arquipélago Norte e Oeste) e fortemente ácido (Arquipélago Sul), enquanto o $\mathrm{Al}^{3+}$ apresentou-se alto. Portanto esses componentes são fatores limitantes ao desenvolvimento da maioria das plantas. Os valores de alumínio se apresentam maiores ao norte, influenciando os resultados, permitindo maior saturação do íon alumínio, diminuindo a saturação por bases.

Não houve diferença significativa na concentração de $\mathrm{P}$ nos arquipélagos avaliados e todos os valores foram classificados como "médio". Tratando-se das bases trocáveis, a partir da média dos resultados foram obtidos valores médios de $\mathrm{Ca}^{+2}$ e altos de $\mathrm{Mg}^{+2}$ nos três arquipélagos, sendo o teor de $\mathrm{Mg}^{+}$superior nas ilhas do sul. $\mathrm{O} \mathrm{K}^{+}$, por outro lado, apresentou valores considerados altos nos Arquipélagos Sul e Oeste, e muito alto na região norte das ilhas. Os valores do $\mathrm{Al}^{+3}$ seguiu o mesmo padrão das bases e da CTC. 
FIGURA 2: Valores médios obtidos para $\mathrm{pH}, \mathrm{P}, \mathrm{Ca}^{+2}, \mathrm{Mg}^{+2}, \mathrm{~K}^{+}$e $\mathrm{Al}^{+3}, \mathrm{SB}$ e CTC nos três arquipélagos.

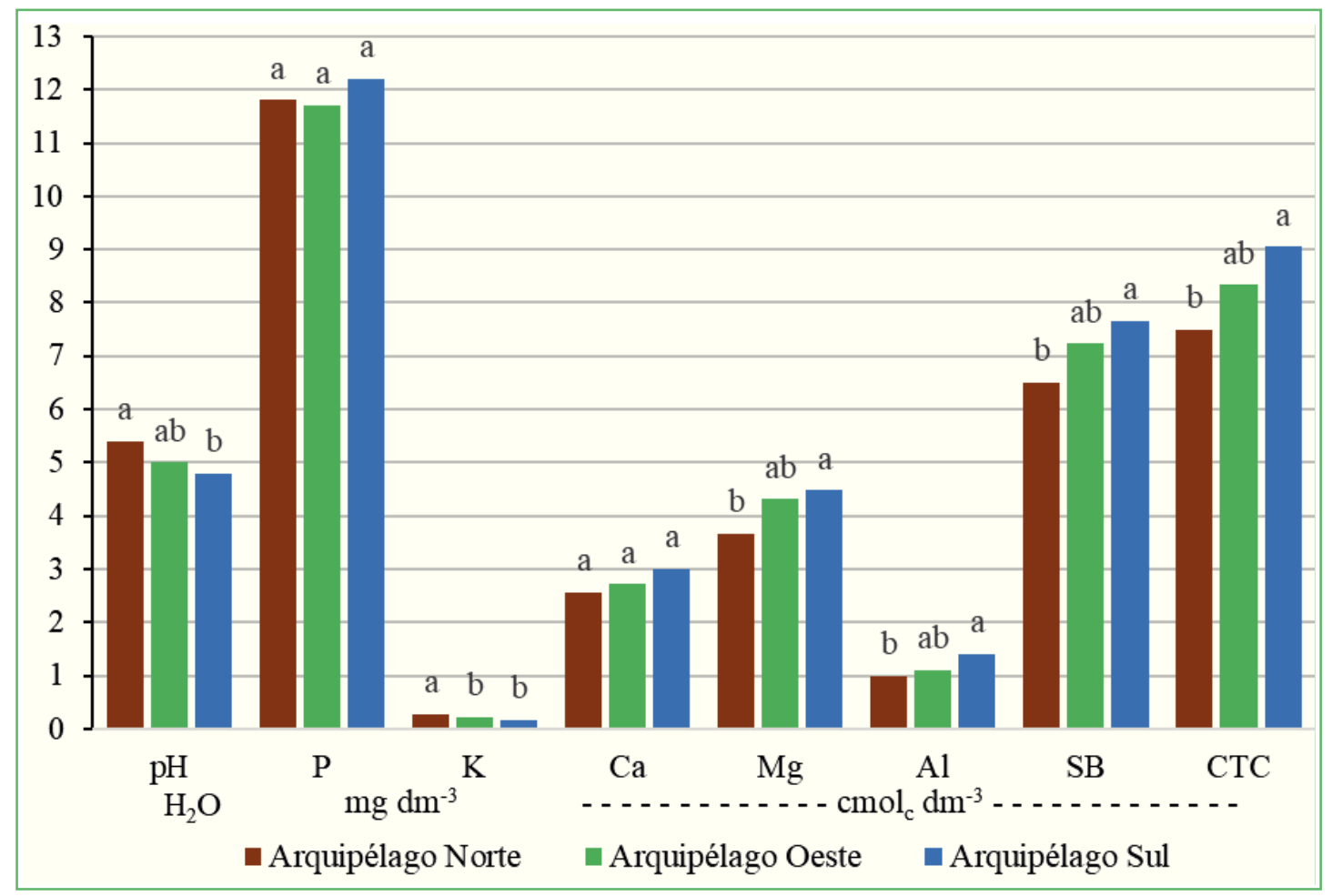

SB - Soma de Bases; CTC - Capacidade de Troca Catiônica; Barras com letras distintas dentro de cada variável representa variação significativa entre si pelo teste de Tukey ao nível de $5 \%$ de significância $(\mathrm{p}<0,5)$.

A capacidade de troca de cátions (CTC) ocorreu com valores reduzidos. A menor média foi obtida no Arquipélago Norte, mas com valores muito próximos da média obtida nos Arquipélagos Oeste e Sul, variando de 7,5 $\mathrm{cmol}_{\mathrm{c}} \mathrm{dm}^{-3}$ a 9,08 $\mathrm{cmol}_{\mathrm{c}} \mathrm{dm}^{-3}$, valor considerado baixo e aproximado à CTC da caulinita. No entanto, calculando-se a saturação por bases (V\%) e a saturação por alumínio (m\%), obteveram-se valores entre 84,5 e $86,8 \%$, o que caracteriza o solo como eutrófico no ambiente insular de Belém. A saturação por alumínio foi de pequena proporção, demonstrando a baixa influência desse íon no solo.

Os solos estudados apresentaram textura semelhante nos três arquipélagos, possuindo maior presença de silte e argila e menor contribuição da fração areia. A textura dos solos das ilhas pode ser melhor observada na Figura 3.

\section{Discussão}

Melo et al. (2013), realizando a caracterização química de solos com diferentes coberturas vegetais, encontraram $\mathrm{pH}$ equivalente a 5,38 em área de várzea, isto é, também indicando reduzida acidez natural dos solos dessas áreas.

O Rio Pará é foz do Rio Guamá e do Rio Acará, que recebem contribuições pelas cidades onde passam, o que pode influenciar com maior intensidade os Arquipélagos Sul e Oeste para finalmente se encontrar com o Arquipélago Norte, misturando suas águas na imensa baía do Marajó, justificando, dessa forma, os altos teores de fósforo nos solos do Arquipélago Sul. Ounissi et al. (2014), estudando valores de $\mathrm{PO}_{4}$, nitrogênio orgânico dissolvido e ácido silícico em dois estuários, encontraram que os teores de $\mathrm{PO}_{4}$ eram maiores no ambiente com influências diversas se comparado ao ambiente sem influências externas. 
FIGURA 3: Granulometria do solo da Ilha de Caratateua (Arquipélago Sul), Ilha Longa (Arquipélago Oeste) e Ilha de Mosqueiro (Arquipélago Norte).

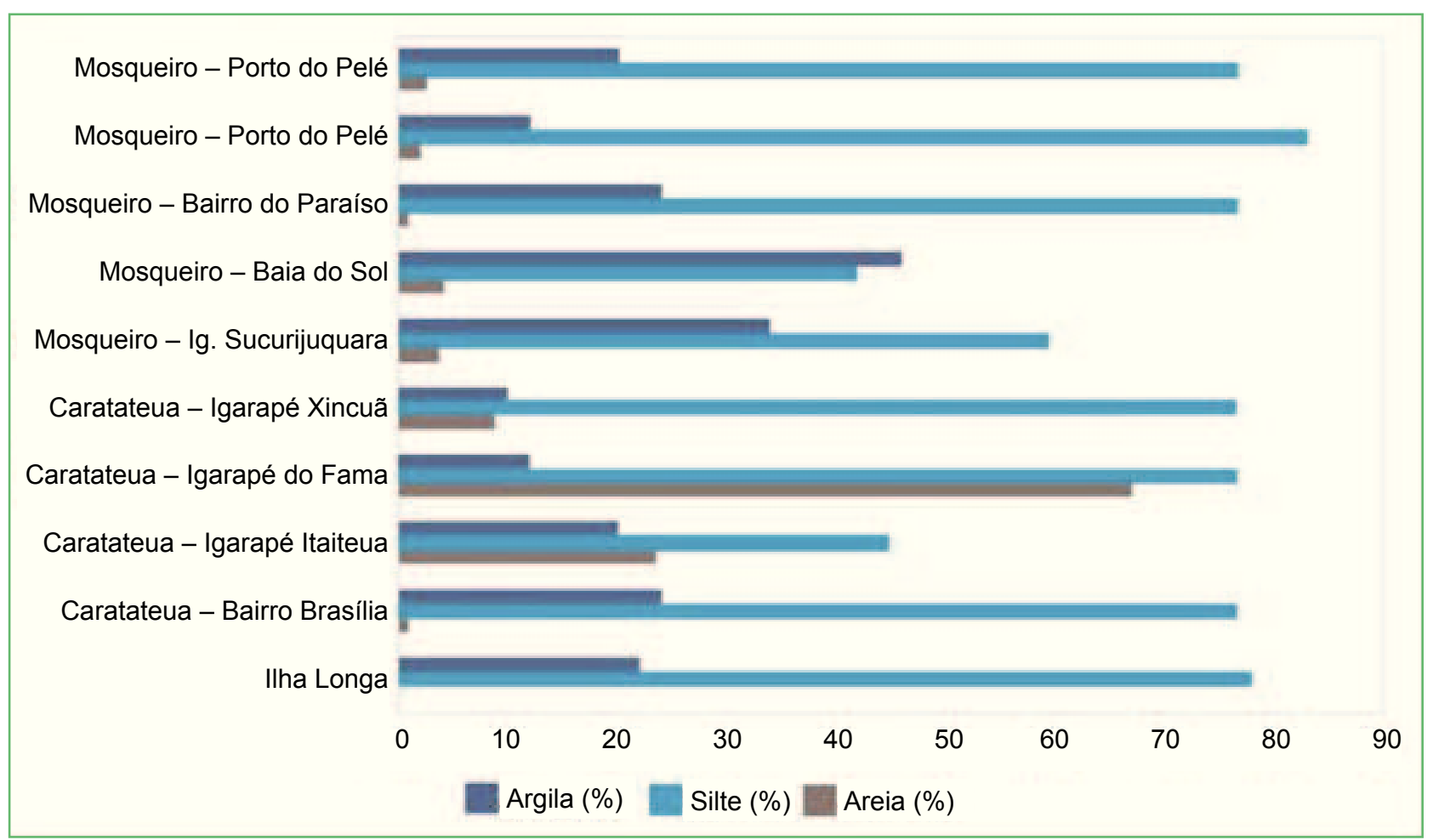

A fertilidade do solo pode estar sendo alterada pelo ambiente e pela contribuição dos sais dissolvidos na água para o complexo solúvel e pode ser notado pela variação dos resultados nos três ambientes estudados (SANTOS et al., 2013). Embora a fertilidade tenha sido alterada, a uniformidade dos ambientes de várzea se mantém em níveis adequados à manutenção da diversidade vegetal.

Embora os solos apresentem fertilidade satisfatória, os valores de $\mathrm{K}^{+}, \mathrm{Mg}^{+2}$ e $\mathrm{Al}^{+3}$ são diferentes e maiores nas ilhas ao sul. Essa diferença pode ser atribuída à movimentação das águas, que provoca a movimentação da zona salobra do estuário para as ilhas que se localizam ao norte da cidade.

Abreu et al. (2007), caracterizando química e fisicamente um gleissolo húmico cultivado com espécies forrageiras, nas proximidades do Rio Guamá, obtiveram teores elevados de $\mathrm{Al}^{+3}$ em período de baixa do lençol freático e valores mais reduzidos desse elemento quando o solo se encontrava em período de maior inundação. Assim, nota-se que o alumínio é diretamente afetado pela condição hídrica do local, onde uma quantidade maior de água o desfavorece. Vários autores destacam os fatores que afetam a fertilidade de solos de várzea. Santos e Salcedo (2010) demonstraram, como exemplo, a textura fina, ao comparar solos com predomínio de frações grosseiras em relação a solos com predomínio de silte ou argilominerais.

Abreu et al. (2007) também encontraram proporções maiores das frações silte e argila em relação à fração areia. Isso pode ser justificado porque, conforme Lima e Tourinho (1996), a sedimentação das partículas ocorre de maneira diferenciada entre as frações que compõem o solo, em que partículas maiores sedimentam-se próximo às margens, em várzeas altas; em seguida, as mais finas são sedimentadas em várzeas baixas; e, por último, as partículas finíssimas são transportadas para as áreas de igapó.

Outra justificativa para a predominância de silte e argila em áreas de várzea relaciona-se ao nível elevado do lençol freático e à inundação constante do local, que provocam limitações ao processo de pedogênese, causando a formação de solos jovens (LIMA, 2001). 
A partir dos resultados obtidos, foi possível concluir que:

- existe variabilidade na fertilidade do solo no ambiente insular de Belém.

- o Arquipélago Sul apresentou os maiores teores de $\mathrm{P}, \mathrm{Ca}^{+2}, \mathrm{Mg}^{+2}, \mathrm{e} \mathrm{Al}^{+3}$, além da $\mathrm{SB}$ e CTC.

- há um gradiente decrescente na direção sul-norte para o $\mathrm{K}+\mathrm{e} o \mathrm{pH}$.

\section{Referências}

ABREU, E. M. A.; FERNANDES, A. R.; RUIVO, M. L. P. Variação temporal e vertical de atributos químicos de um gleissolo do Rio Guamá cultivado com canaranas. Revista Brasileira de Ciência do Solo, Viçosa, v. 31, p. 277-285, 2007.

CRAVO, M. S.; VIÉGAS, I. J. M.; BRASIL, E. C. Recomendações de adubação e calagem para o Estado do Pará. Belém: Embrapa Amazônia Oriental, 2007. 262 p.

EMBRAPA. Manual de análises químicas de solos, plantas e fertilizantes. Brasília: Embrapa Informação Tecnológica, 2009. $627 \mathrm{p}$.

FERREIRA, D. S. Dinâmica socioespacial em comunidades ribeirinhas das ilhas de Abaetetuba-PA. 2014. 168 f. Dissertação (Mestrado em Geografia) - Universidade Federal do Pará, Belém. 2014.

LIMA, H. N. Gênese, química, mineralogia e micromorfologia de solos da Amazônia Ocidental. 2001. 176 f. Tese (Doutorado em Solos e Nutrição de Plantas) - Universidade Federal de Viçosa, Viçosa. 2001.
LIMA, R. R.; TOURINHO, M. M. Várzeas do Rio Pará, principais características e possibilidades agropecuárias. Belém: FCAP, 1996. 124 p.

LIMA, R. R.; TOURINHO, M. M.; COSTA, J. P. C. Várzeas flúviomarinhas da Amazônia brasileira: características e possibilidades agropecuárias. Belém: FCAP, 2001. 342 p.

MELO, N. C.; SOUZA, L. C.; COSTA, C. A. S.; COELHO, R.; COVRE, W. P.; COSTA, D. L. P. Caracterização química de diferentes sistemas de uso do solo. Revista Agroecossistemas, Belém, v. 5, n. 2, p. 8-13, 2013.

OUNISSI, M.; ZIOUCH, O. R.; AOUNALLAH, O. Variability of dissolved nutrient (N, P, Si) concentrations in the Bay of Annaba in relation to the imputs of the seabouse and Mafragh estuaries. Marine Pollution Bouletin, Amsterdam, v. 80, n. 1-2, p. 234-244, 2014.

SANTOS, A. C. dos; SALCEDO, I. H. Fertilidade nas áreas de várzeas e topo em função do uso do solo e posição do relevo. Revista de Biologia e Ciências da Terra, Campina Grande, v. 10, n. 2, p. 83-90, 2010.

SANTOS, M. A dos; FREIRE, M. B. G. dos S.; ALMEIDA, B. G.; LINS, C. M. T.; SILVA, E. M. Dinâmica de íons em solo salinosódico sob fitorremediação com Atriplex nummularia e aplicação de gesso. Revista Brasileira de Engenharia Agrícola e Ambiental, Campina Grande, v. 17, n. 4, p. 397-404, 2013.

SILVA, S. B. Análise de solos. Belém: Universidade Federal Rural da Amazônia, 2003. 152 p.

SILVA, S. S. C.; PONTES, F.A. R.; SANTOS, T. M.; MALUSCHKE, J. B.; MENDES, L. S. A.; REIS, D. C.; SILVA, S. D. B. Rotinas familiares de ribeirinhos amazônicos: uma possibilidade de investigação. Psicologia: Teoria e Pesquisa, Brasília, v. 26 n. 2, p. 341-350, 2010. 